Article

\title{
An Empirical Study on the Design of China High-Speed Rail Express Train Operation Plan-From a Sustainable Transport Perspective
}

\author{
Xueqiao $\mathrm{Yu}^{1}{ }^{1}$, Maoxiang Lang ${ }^{1,2, *}$, Yang Gao ${ }^{3}$, Kai Wang ${ }^{4}$, Ching-Hsia Su ${ }^{5, *}$, \\ Sang-Bing Tsai ${ }^{4,6} \mathbb{C}^{\mathbb{D}}$, Mingkun Huo ${ }^{7}$, Xiao $\mathrm{Yu}^{8}$ and Shiqi $\mathrm{Li}^{1}$ \\ 1 School of Traffic and Transportation, Beijing Jiaotong University, Beijing 100044, China;

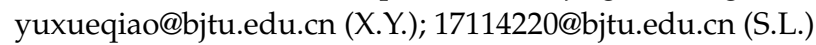 \\ 2 MOE Key Laboratory for Urban Transportation Complex System Theory and Technology, \\ Beijing Jiaotong University, Beijing 100044, China \\ 3 School of Business, Dalian University of Technology, Panjin 124221, China; gzm@dlut.edu.cn \\ 4 College of Business Administration, Capital University of Economics and Business, Beijing 100070, China; \\ wangkai@cueb.edu.cn (K.W.); sangbing@hotmail.com (S.-B.T.) \\ 5 College of Tourism and Service Management, Nankai University, Tianjin 300071, China \\ 6 Zhongshan Institute, University of Electronic Science and Technology of China, Zhongshan 528400, China \\ 7 Zhong Zi Hua Ke Traffic Construction Technology Co. Ltd., Beijing 100195, China; \\ huomingkun1127@163.com \\ 8 Signal and Communication Research Institute, China Academy of Railway Sciences Corporation Limited, \\ Beijing 100044, China; luck1036@163.com \\ * Correspondence: mxlang@bjtu.edu.cn (M.L.); maysky566@gmail.com (C.-H.S.)
}

Received: 17 May 2018; Accepted: 12 July 2018; Published: 16 July 2018

\begin{abstract}
The sustained and steady development of China's economy has led to the rapid improvement of the logistics. At the same time, the rise of the e-commerce mode has given rise to a huge demand for express delivery and the express industry has entered a period of boom. Fortunately, China's high-speed rail network has been networked, and the development of a high-speed rail express train has entered the test stage. After the high-speed rail express train is put into use, it could effectively relieve the pressure of highway transportation and significantly reduce transport pollution. To make better use of high-speed rail transport resources and give full play to its green and efficient advantages, this study established a two-stage model of a high-speed rail express train operation plan. In the first stage, a train candidate set generation model aiming for the minimum total cost of train operation was established that considered the high-speed line carrying capacity, section flow capacity, and OD requirement satisfaction constraints, which reduces the scale of train spare parts and improves the efficiency of solution. In addition, a column generation algorithm was designed to solve the model. In the second stage, an accurate flow distribution model aiming for the optimal economic efficiency was established, and then the high-speed express train operation plan was designed completely. The computational results are encouraging and demonstrate the effectiveness of the model and solution method.
\end{abstract}

Keywords: high-speed rail express; train operation plan; column generation algorithm; sustainable transportation; sustainability

\section{Introduction}

There is a huge transportation demand in China's express transportation market. In 2016, China's express delivery volume exceeded 30 billion for the first time, reaching 31.28 billion, an increase of 
$51.4 \%$ year-on-year, ranking at the forefront of the modern service industry and becoming the highlight of China's new economy. China's express delivery volume has been increasing year by year, and its income has also been continuously increasing. China's express delivery volume and revenue for 2008-2016 are shown in Figure 1.

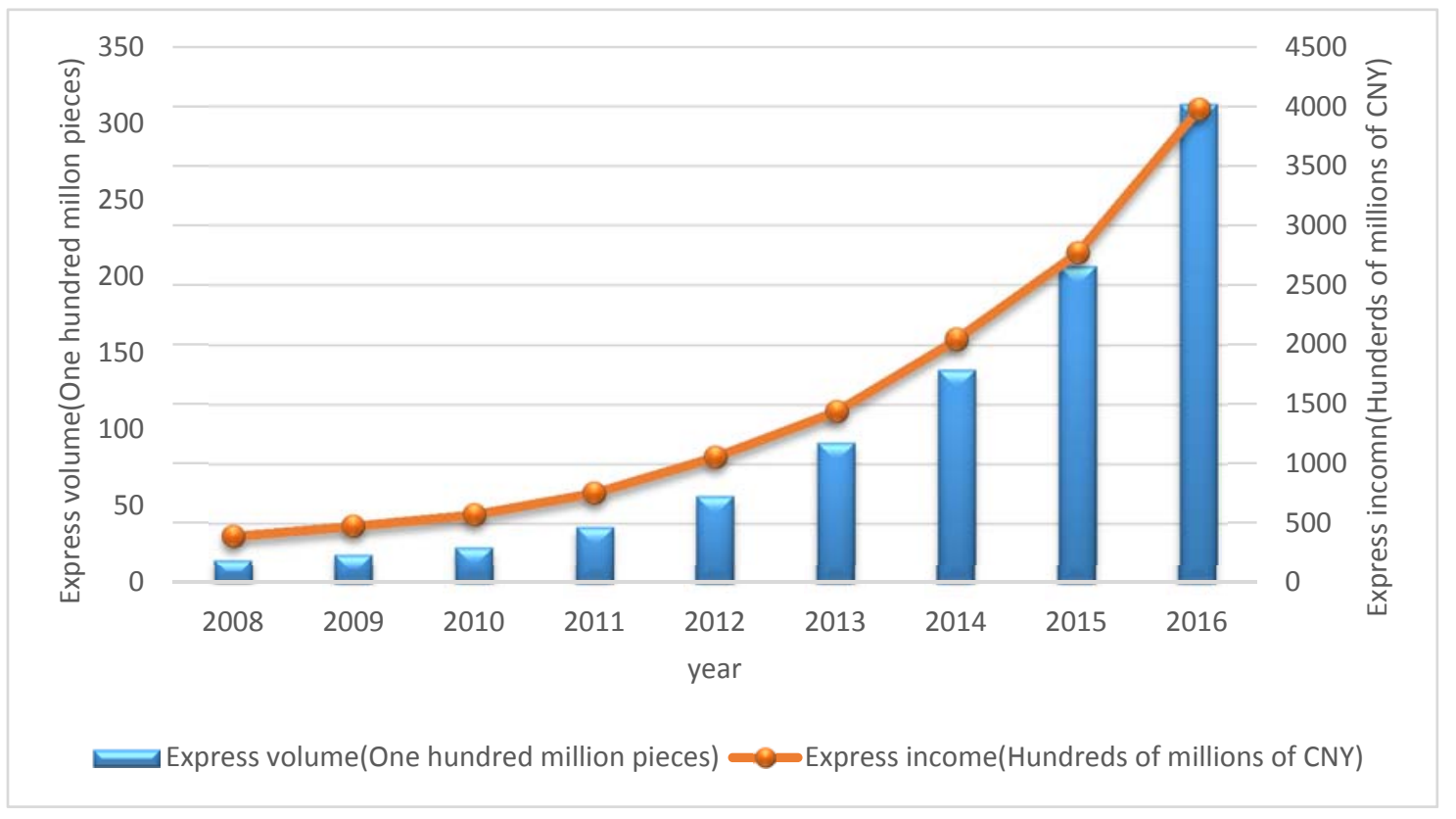

Figure 1. The volume and income of express delivery during 2008-2016.

As a green transportation mode, high-speed railway has advantages that other transportation modes do not have in express transportation [1]. At the same time, in the face of huge market demand, the China Railway Corporation has made use of high-speed passenger trains and point to point high-speed railway confirmation trains to enter the express transportation market, but its market share is still less than 1\%, and many advantages of express transportation in China's high-speed railway have not been fully distributed. To solve the problems of insufficient capacity of high-speed rail passenger trains, impact on passengers, and the short transportation interval of high-speed rail confirmation trains, China Railway Corporation has developed $250-350 \mathrm{~km} / \mathrm{h}$ freight trains to make full use of the huge network capacity of high-speed railway and reduce the cost of goods flow in express delivery service.

On the other hand, more than $90 \%$ of China's express delivery service is completed by highway, where the traffic congestion and environmental pollution have been paid increased attention [2]. The advantages of large volume and low pollution of high-speed railway express trains will effectively alleviate the pollution problem of express transportation. Meanwhile, the high-speed rail express train will better meet the needs of the timely delivery of goods with its advantages of speed, punctuality, and safety. The reasonable operating mode and plan of a high-speed rail express train can be adapted to the development of a macro economy. It can provide low cost, environmental protection, and fast transportation service for the express transportation market, which has great economic and social benefits. Therefore, this study designed a high-speed railway express train operation plan to ensure the balance between demand and supply.

To ensure that the demand is satisfied and the train running income of the railway enterprise, this study constructed a two-stage model of the high-speed rail express train opening plan, and designed a column generation algorithm to solve the model. The remainder of this paper is organized as follows. The Section 2 introduces the related research review. Section 3 establishes the train candidate set generation model of a high-speed railway express train. In Section 4, an algorithm 
designed to solve the model is presented. Section 5 presents the construction of a high-speed express train flow distribution model. Finally, an example is used to generate the high-speed railway express train operation plan.

\section{Literature Review}

The study of railway freight operation and management in developed countries is very thorough. Seung-Ju [3] put forward the core issues of railway freight transportation including determining the transportation route, service frequency, train marshalling, and transportation volume. Troche [4] studied the operation advantage of high-speed rail freight, and proposed competing with other modes of transportation as one of the operational objectives, and analyzed the organization method of high-speed rail freight transport based on train working diagram windows. Pazour [5] proposed a scheme to improve highway congestion by transportation of high-speed rail goods. By analyzing the distribution of freight, a high-speed rail freight node model was established to reduce transportation time and road transport pressure.

At present, the research into train operation plan designs for high-speed railway is very rich, and has mainly adopted three schemes to design the train operation plan: the integer programming model, 0-1 planning model, and network analysis model.

Among them, the integer programming model is a classic optimization model for an express freight transport operation plan. Fukasawa [6] established the network flow model of various kinds of goods based on optimizing the heavy and empty train flow, which maximized the transportation efficiency based on meeting the customer's demand, and finally obtained the transportation distribution of various transportation routes. Racunica [7] believed that the transport mode between OD was divided into two types, direct delivery and transfer, and the relationship between transportation cost and transport volume was linear and exponential. Based on this, a nonlinear mixed integer model was established.

For the 0-1 planning model, Cao [8] solved the feasibility of the freight through trains. Considering the transportation and inventory, a nonlinear 0-1 programming model was established to optimize the train operation. Liang [9] considered the condition of the group train formed by merging or connecting a single set of trains, constructed a mathematical model of optimizing strategically dynamic train operation, which was combined with loaded and empty car distribution, and brought the impact of loading capacity, unloading capacity, classification capacity, delivery capacity, and transport instruction into optimization.

The network analysis model applies the classical graph theory in operational research to rationally arrange the nodes of the train formation or adaptation to achieve the goal of the minimum total cost of traffic. $\mathrm{Li}$ [10] used the theory of graph and network to analyze the problem of the train marshalling plan. To minimize the total cost of railway traffic, a single target model was set up, and a solution algorithm was designed. Li [11] analyzed the method of forming the plan based on the express freight network, and then they put forward the goal of organizing the express freight train and optimization method of a marshalling plan for the express freight train.

Some studies have considered the impact of high-speed railway passenger trains on the freight train operation plan. Godwin [12] formulated the time adjustment strategy of freight trains that aimed to ensure the safety of passenger trains, and, based on the dynamic dispatching model of freight trains, designed the train operation plan method under the mixed passenger and freight railway. Wojciech [13] considered the passenger train timetable and safety time interval, and calculated the shortest route of a freight train in a railway network based on the Dijkstra algorithm. The superiority of the algorithm in large railway network has been proven by empirical calculation, which is very practical. Kaspi [14] designed the calculation method of freight transport convenience where the main reference was to estimate the transfer cost of passenger transport, and then established a two objective train operation plan model with the lowest operation cost and the highest convenience before finally designing a heuristic algorithm. 
As can be seen from the above, experts and scholars have conducted many studies on different types of trains such as high-speed railway passenger trains, ordinary passenger trains, freight trains, and mail and luggage vans, but there are still some defects in the design of a high-speed railway express train. Therefore, it is necessary to study the contents of the train operation plan including the operating time of the train, the proportion of different kinds of trains, the operation frequency, and the stop schedule plan [15-20].

China's high-speed rail network is a large-scale and complex network that contains many sites, resulting in a large collection of routes for trains. Therefore, when solving the mixed integer programming model established in this study, the computation time is too long, and even the optimal solution is not acceptable [21-25]. To address this problem, this study designed a column generation algorithm to minimize the cost of train running by considering the capacity ability, the relationship between train load and loading capacity and the OD requirements to obtain a train candidate set, which could reduce the size of the solution for the next stage of the model [26-28].

In the second stage, we needed to consider the income of the railway enterprises, so the maximum of the difference between the income and the cost was taken as the objective to determine the running section, stop schedule plan, and quantity of trains, which ensured we completed the OD requirements in a more profitable way.

\section{Train Candidate Set Model Formulation}

\subsection{Problem Description}

Under the conditions of high-speed railway network operation, different routes can be chosen between the two sites, and different routes have a different stop schedule plan, which will produce many train types. In the actual operation process, some running sections do not meet the principle of the train operating plan: (1) some programs have a too close origin-destination for trains, which will result in a high fixed cost for operating such trains; (2) some programs may deviate greatly from the flow of goods, which leads to excessive waste of the capacity in the section of trains; and (3) some schemes do not consider the co-optimization of trains, which leads to repeat operations in some sections.

Therefore, to avoid these unreasonable situations, reduce the scale of the case, and improve the efficiency of solving, this study established a train candidate set model that aimed to obtain a set of candidate routes that met the needs of freight transport and the economic and technical requirements of train operation. The first stage of the model used the minimum cost of train operation as the objective by considering factors such as carrying capacity, loading capacity, and OD demand, which is the basis for further research into the train operation frequency and loading plan.

\subsection{Model Hypothesis}

Based on the development status of China's high-speed rail and the organization characteristics of the train operation, this paper makes the following hypothesis.

(1) At present, China's high-speed rail transport is limited by the capacity of the operation site, and there is a problem that facilities and equipment do not match. However, with the use of high-speed rail express trains, it is necessary to reform the stations. Therefore, in the design phase of the operation plan, this paper assumes that all stations can organize high-speed rail transportation.

(2) The operation of high-speed rail express trains does not conflict with high-speed train passenger trains.

(3) The high-speed rail express train operation plan does not consider the problem of vehicle bottom utilization.

(4) Within a certain period, the demand for high-speed rail transport will not change. 


\subsection{Model Formulation}

The cost of train operation is always expected to be able to meet both the demand of the source and the savings of the total cost. Therefore, to minimize the total cost of the train operation, this study built a candidate set model of high-speed rail express trains, which is as follows:

OBJ:

$$
\operatorname{MinZ} Z_{1}=\sum_{i \in F} f_{i} \times\left(c_{i}^{T}+\sum_{(j, k) \in \mathcal{E}} c_{i}^{V} \cdot z_{j k} \cdot d_{j k}^{i}+\sum_{s \in \phi} x_{s} \cdot c_{i}^{s}\right)
$$

S.t.

$$
\begin{gathered}
\sum_{i \in T} f_{i} \times z_{j k}^{i} \leq C_{r s} \forall(j, k) \in \varepsilon \\
\sum_{i \in T} f_{i} \times V_{i} \times z_{j k}^{i} \geq \sum_{\omega \in \Omega r s} Q_{\omega} \forall(j, k) \in \varepsilon \\
\sum_{i \in T} f_{i} \times y_{i}^{\omega} \times M \geq Q_{\omega} \forall \omega \in \Omega
\end{gathered}
$$

Equation (1) indicates that the objective is to minimize the total cost of the train operation, i.e., the total cost of the total operating of the train in different intervals is the smallest including the fixed cost of the single train, the cost related to the distance, and the total stop cost.

Equation (2) represents the train passing capacity constraint. The carrying capacity of the train is limited by the capacity of the fixed equipment. For freight trains running on high-speed railways, they are also affected by the characteristics of high-speed railway transport organization. As the high-speed railway is mainly a passenger train, it can be reserved as the high-speed railway express train working diagram space is very limited. In addition, the busy degree of passenger transport in each section is different, so the space that can be reserved for high-speed railway express train will also be different. Therefore, when designing the high-speed railway express train operation plan, it is necessary to coordinate the difference of the capacity of each section and reasonably determine the origin and destination points of the train to make full use of the carrying capacity, as shown in Figure 2.

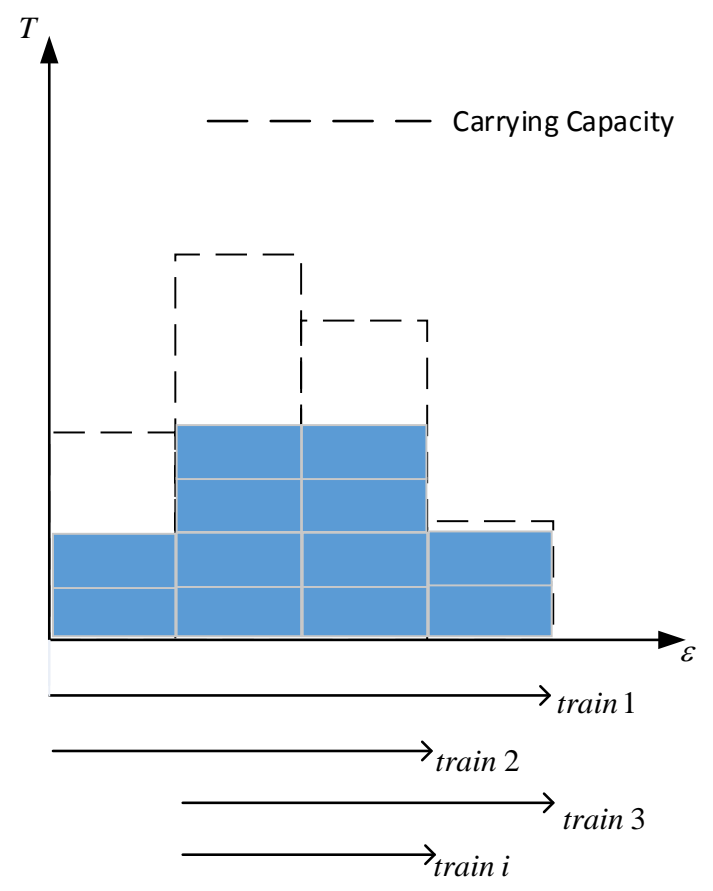

Figure 2. The constraint of the section capacity ability. 
Equation (3) represents the demands satisfaction constraint. The ability of unit time through a section of the flow depends on the ability of mobile devices. The service frequency and loading capacity of the train need to cover the demand. That is, on each section of the train running path, the total freight load of each train cannot exceed the total loading capacity of the train, which requires us to reasonably design the loading plan of the train to ensure that all the demands can be satisfied in each section. The relationship between train loading capacity and customer demand is shown in Figure 3.

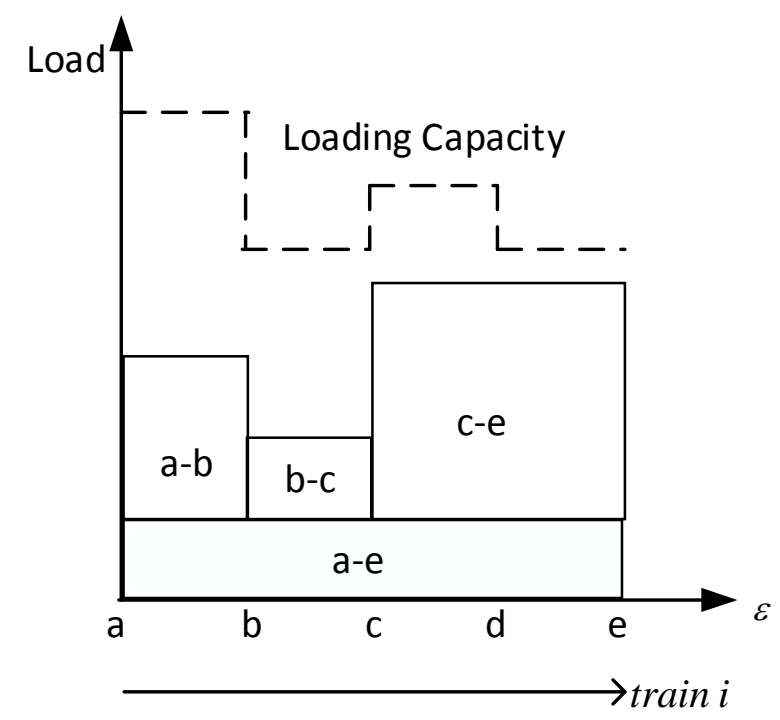

Figure 3. The relationship between train load and loading capacity.

Equation (4) represents the OD requirements constraints, which means that, as long as an OD has freight transport demand, there must be a train serving it.

\section{A Column Generation Algorithm for Train Candidate Set Generation Model}

The train candidate set generation model is a nonlinear programming model, which is difficult to solve directly. Therefore, this study designed a column generation algorithm to solve it, aiming to reduce the size of the problem in the distribution of cargo flow.

\subsection{Algorithm Principle and Low}

The column generation algorithm was developed based on solving the simple method of linear programming. When we use the simplex method to solve the problem, the steps are as follows:

In Figure 4, we can see that the test number is the key factor for the simplex method to obtain the optimal solution. The traditional simplex method needs to calculate the number of tests after each iteration to determine the optimality of the results. The column generation algorithm does not need to complete the whole simple table, but constructs a model that uses the "test number" as the objective function. The new model is solved repeatedly until the target function is less than or equal to 0 to satisfy the iterative rules in Figure 4.

Therefore, according to the iteration principle of the simplex method, we can obtain the flow of the column generation algorithm, as shown in Figure 5. 


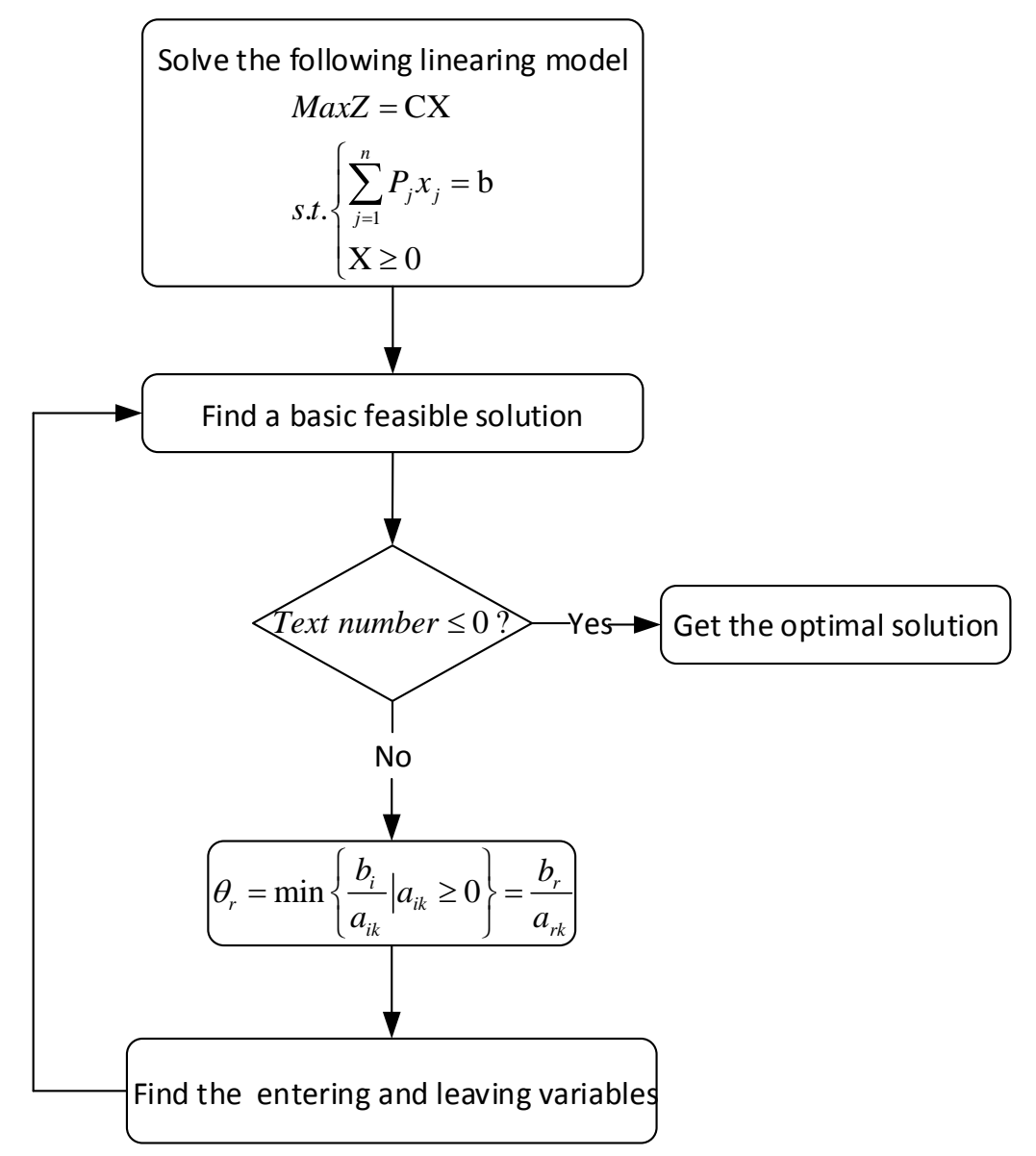

Figure 4. Solving steps of simple method.

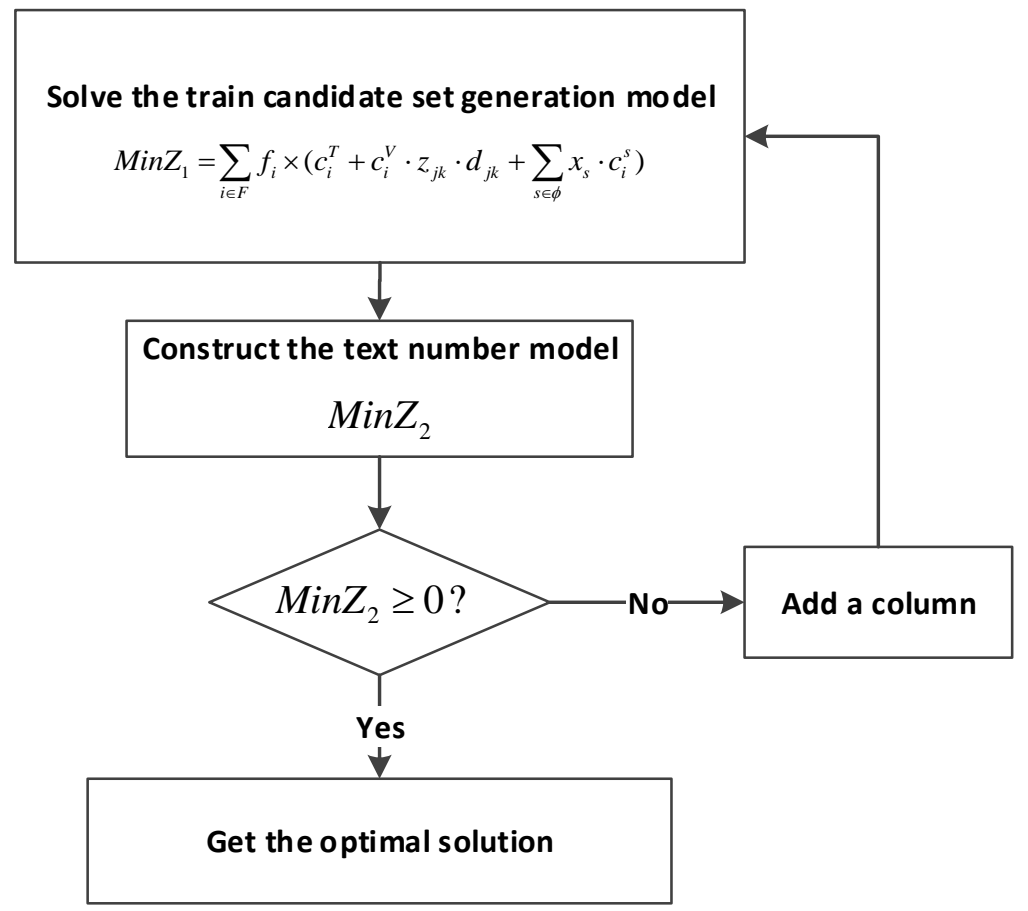

Figure 5. Column generation algorithm flow. 


\subsection{The Sub Problem Formulation of the Column Generation Algorithm}

\section{(1) Objective function}

The key to solving the train candidate set generation model with the column generation algorithm is to construct a test number sub problem model, which means that, when we select the largest text number of basic entries, the coefficient of the column is determined by the sub problem. According to the iterative rule of the simplex method, the iteration will be stopped until the test number of the objective function of the sub problem is non-positive. Therefore, using $\pi_{j k}, \rho_{j k}, \eta_{\omega}$ to represent the value of the constraints in Equations (2)-(4), respectively, the test number sub problem model's objective function is as follows:

$$
\begin{gathered}
\operatorname{MinZ}_{2}=\left(\sum_{i \in T} c_{i}^{T}+\sum_{(j, k) \in \varepsilon} c_{i}^{V} \cdot z_{j k} \cdot d_{j k}^{i}+\sum_{s \in \phi} x_{s} \cdot c_{i}^{s}\right)- \\
\sum_{(j, k) \in \mathcal{\varepsilon}} \pi_{j k} \cdot z_{j k}+\sum_{(j, k) \in \mathcal{\varepsilon}} \rho_{j k} \cdot z_{j k} \cdot V_{i}+\sum_{\omega \in \Omega} \eta_{\omega} \cdot y_{\omega} \cdot M
\end{gathered}
$$

(2) Constraint conditions

(a) The relationship between service and stop constraints

It is necessary to ensure that all trains serving at $\omega$ should stop at the starting point and terminal point of $\omega$. Therefore, the relationship between service and stop constraints can be expressed as follows:

$$
\begin{gathered}
y_{i}^{\omega} \leq x_{i}^{O_{\omega}} \forall \omega \in \Omega, \forall i \in T \\
x_{i}^{O_{\omega}}+x_{i}^{D \omega}-y_{i}^{\omega} \leq 1 \quad \forall \omega \in \Omega, \forall i \in T
\end{gathered}
$$

(b) Train stop times constraint

To ensure the section passing capacity and the efficiency of freight transportation, the number of stops should be limited, which is expressed as follows:

$$
\sum_{s \in \phi} x_{i}^{s} \leq \alpha \forall i \in T
$$

(c) Train stop and starting and destination point constraint

Firstly, we need to ensure that there is only one starting point and one end point. Secondly, the train serving the OD must stop at the starting point and terminal point of this OD pair. These are expressed as follows:

$$
\begin{gathered}
\sum_{s \in \phi} k_{s}^{O / D_{\omega}}=1 \forall \omega \in \Omega, \forall s \in \phi \\
2-x_{i}^{O \omega}-x_{i}^{D_{\omega}} \leq 0 \forall \omega \in \Omega, \forall i \in T \\
1-k_{s}^{O / D_{\omega}} \geq 1-x_{i}^{s} \forall i \in T, \forall \omega \in \Omega
\end{gathered}
$$

Among them, Constraint (9) indicates that there is only one origin and destination point of the same OD. Constraints (10) and (11) indicate the relationship between the OD and the train stops, that is, at the starting and ending points it must be stopped.

(d) Train running path constraint 
To constrain the train's running path, first, it is necessary to ensure that the stop of the train will not exceed the range of OD, and, secondly, the train passing section cannot be outside OD yet, which are expressed as follows:

$$
\begin{gathered}
\sum_{n=1}^{s-1} x_{i}^{s-n} \leq\left(1-k_{s}^{O_{\omega}}\right) \cdot M \forall s \in \phi, \forall \omega \in \Omega, \forall i \in T \\
\sum_{n=1}^{\phi-s} x_{i}^{s+n} \leq\left(1-k_{s}^{D_{\omega}}\right) \cdot M \forall s \in \phi, \forall \omega \in \Omega, \forall i \in T \\
2 z_{j r}^{i} \leq \sum_{n=1}^{j-1} k_{j-n}^{O_{\omega}}+\sum_{n=1}^{\phi-r} k_{r+n}^{D_{\omega}} \forall(j, r) \in \varepsilon, \forall \omega \in \Omega, \forall i \in T
\end{gathered}
$$

Constraints (12) and (13) indicate that no stops are allowed outside the origin and destination. Constraint (14) indicates the relationship between the train passing section and the origin and destination point, that is, the train cannot go through the section beyond the origin destination point.

(e) Decision variables constraint

$$
\begin{gathered}
0 \leq x_{i}^{s} \leq 1 x_{i}^{s} \in N \\
0 \leq y_{i}^{\omega} \leq 1 y_{i}^{\omega} \in N \\
0 \leq z_{j r}^{i} \leq 1 z_{j r}^{i} \in N \\
0 \leq k_{s}^{O_{\omega}} \leq 1 k_{s}^{O_{\omega}} \in N
\end{gathered}
$$

\section{The Cargo Flow Distribution Model Formulation}

\subsection{Problem Description}

After completing the first stage train candidate set generation model, we enter the second stage of the train operation plan, that is, the cargo distribution stage. In the first stage, we have only eliminated the illogical and overpriced sections, and the choice of the train is only given for which kinds of trains can be operated, but no specific trains are selected and there is no calculation of how much cargo per train is loaded.

Therefore, the second stage of the cargo flow distribution model will specifically calculate the train type, frequency, and stop plan of the train operation plan. At this stage, we need to consider the costs and benefits of train operation, rather than simply considering the cost of trains in the first stage. In addition, in the first stage, we only considered the capacity constraints, without specific consideration of the distribution of cargo, so, in the second stage, in the case of a single load quality not more than its carrying capacity, we have to ensure that the minimum number of trains will meet the needs of each OD to ensure the accurate distribution of the cargo flow.

\subsection{Model Formulation}

Through the first stage of path selection, the train candidate set has been identified as those reasonable paths. The second stage model is mainly to solve the problem of how to design a train operation plan after a given train candidate set, which can gain more profit and meet the demand of freight. Therefore, the model can be expressed as follows:

Obj:

$$
\begin{gathered}
\operatorname{Max} Z_{3}=\sum_{\omega \in \Omega} \sum_{i \in T} p_{\omega} \cdot q_{\omega}^{i}-\sum_{\omega \in \Omega} \sum_{i \in T} c^{L} \cdot q_{\omega}^{i} \\
-f_{i} \cdot\left(\sum_{i \in T} c_{i}^{T}+\sum_{(j, k) \in \varepsilon} c_{i}^{V} \cdot z_{j k} \cdot d_{j k}^{i}+\sum_{s \in \phi} x_{s} \cdot c_{i}^{s}\right)
\end{gathered}
$$


such that

$$
\begin{gathered}
\sum_{\omega \in \Omega} \sum_{i \in T} q_{\omega}^{i} \leq \sum_{\omega \in \Omega} Q_{\omega} \\
\sum_{i \in F} \sum_{(j, k) \in \varepsilon} f_{i} \cdot z_{j k}^{i} \leq \sum_{(j, k) \in \varepsilon} C_{j k} \\
\sum_{\omega \in \Omega_{j k}} q_{\omega}^{i} \leq V_{i} \times f_{i} \forall i \in T,(j, k) \in \varepsilon \\
f_{i} \in N \forall i \in T \\
q_{\omega}^{i} \geq 0 \forall \omega \in \Omega, i \in T
\end{gathered}
$$

Among them, objective function in Equation (19) represents the maximum profit of the high-speed railway express train. The first part is to represent the total income of the railway transportation enterprises satisfying the demand of transportation, that is, the sum of the demand and the price of each section. The second part represents the cost of goods loading, which has the meaning of minimizing the number of stops. The third part shows the total cost of train operation including the fixed cost, the distance related cost, and the cost of stopping the station, which means that the train running frequency is as few as possible.

Constraint (20) is the maximum constraint on train utilization, which limits the problem caused by a certain OD for the distribution of excessive trains, and reduces the waste of train capacity to the maximum extent. Constraint (21) represents the limitation of the network capability. In a high-speed railway network, the capability of passing the train is an important limitation for the operation of the high-speed railway express train. Constraint (22) is the constraint of the train loading capacity. Constraint (23) shows that the train running frequency is an integer. Constraint (24) represents that there must be transportation needs between the origin and destination.

\section{Experimental Case Study}

\subsection{Parameter Value}

The Beijing_Shanghai high-speed railway is an important link between Beijing and Shanghai, with a total length of $1318 \mathrm{~km}$, connecting three municipalities directly under the central government, through four provinces, and also connects the Beijing, Tianjin, and Hebei economic regions and the Yangtze River Delta economic regions, which is one of the most active areas in China's economy. Furthermore, it is also a high-speed railway with a busy passenger and freight transport and has great potential for growth. Therefore, by using the Beijing-Shanghai high-speed railway as an example, this study selected six important cities, namely Beijing, Tianjin, Jinan, Xuzhou, Nanjing, and Shanghai, and used the two-stage model given above to design the train operation of the Beijing-Shanghai high-speed railway.

In this study, the speed grade of the high-speed railway express train was the same. The difference of train type $i$ is that the train stops at different stations, which can be divided into each station stop, multi station stop, and direct train. The mode of train stop should be arranged flexibly according to the source OD. At present, the high-speed rail express train designed in this paper has a single marking capacity of $120 \mathrm{t}$. The average daily OD of high-speed rail express between cities is shown in Table 1 .

The fixed $\operatorname{cost} c_{i}^{F}$ for a single train is 420 thousand CNY. In addition to the fixed cost, variable cost is divided into:

1. Train running variable $\operatorname{cost} c_{i}^{V}$ is $700 \mathrm{CNY} / \mathrm{km}$, which is related to distance.

2. Variable $\operatorname{cost} c_{i}^{S}$ is 50 thousand $\mathrm{CNY} /$ times, which is related to the train stop times.

3. The variable $\operatorname{cost} c^{L}$ of loading and unloading the goods at the site is $10 \mathrm{CNY} / \mathrm{ton}$.

It is assumed that the passing capacity $C_{r s}$ of each section can meet the requirements of high-speed rail express train operation. 
Table 1. Daily OD volume of high-speed railway express between cities ( $t$ ).

\begin{tabular}{|c|c|c|c|c|c|c|}
\hline$X$ & Beijing & Tianjin & Jinan & Xuzhou & Nanjing & Shanghai \\
\hline Beijing & - & 73.68 & 153 & 84 & 54 & 160 \\
\hline Tianjin & 74.6 & - & 21 & 15.6 & 8.4 & 18 \\
\hline Jinan & 122.4 & 18.96 & - & 36.6 & 20.64 & 38.64 \\
\hline Xuzhou & 57.96 & 13.56 & 35.28 & - & 29.64 & 67.8 \\
\hline Nanjing & 27.24 & 5.4 & 14.65 & 21.6 & - & 55.2 \\
\hline Shanghai & 317.4 & 64.32 & 153.24 & 297 & 310.8 & - \\
\hline
\end{tabular}

The distance between cities is shown in Table 2 .

Table 2. The distance between major cities $(\mathrm{km})$.

\begin{tabular}{ccccccc}
\hline City & Beijing & Tianjin & Jinan & Xuzhou & Nanjing & Shanghai \\
\hline Beijing & - & 122 & 406 & 692 & 1023 & 1318 \\
Tianjin & 122 & - & 284 & 570 & 901 & 1196 \\
Jinan & 406 & 284 & - & 286 & 617 & 912 \\
Xuzhou & 692 & 570 & 286 & - & 331 & 626 \\
Nanjing & 1023 & 901 & 617 & 331 & - & 295 \\
Shanghai & 1318 & 1196 & 912 & 626 & 295 & - \\
\hline
\end{tabular}

\subsection{The Train Candidate Set Scheme}

In this paper, we used the python language to invoke the CPLEX12.7.1 engine to realize the column generation algorithm. The calculation is performed by a Lenovo Laptop with Intel Core i5 $3235 \mathrm{M} 2.60 \mathrm{GHz}$ CPU and 4 GB RAM. Due to the small scale of the case, the computational time took only $1 \mathrm{~s}$.

In the first stage, we obtained the train candidate set scheme through input model parameters and intercity demand.

(1) The train candidate set scheme in the up direction

A total of 10 trains were generated from the train candidate set scheme in the up direction, as shown in Table 3 and Figure 6.

Table 3. The backup train plans for high-speed rail express in the up direction.

\begin{tabular}{cccc}
\hline Train Number & Origin & Destination & Stop \\
\hline 1 & Shanghai & Beijing & Nanjing, Xuzhou, Jinan, Tianjin \\
2 & Shanghai & Beijing & Xuzhou, Jinan \\
3 & Shanghai & Beijing & Xuzhou \\
4 & Shanghai & Beijing & Jinan \\
5 & Shanghai & Beijing & - \\
6 & Shanghai & Nanjing & - \\
7 & Shanghai & Xuzhou & - \\
8 & Shanghai & Jinan & - \\
9 & Nanjing & Beijing & - \\
10 & Xuzhou & Beijing & - \\
\hline
\end{tabular}




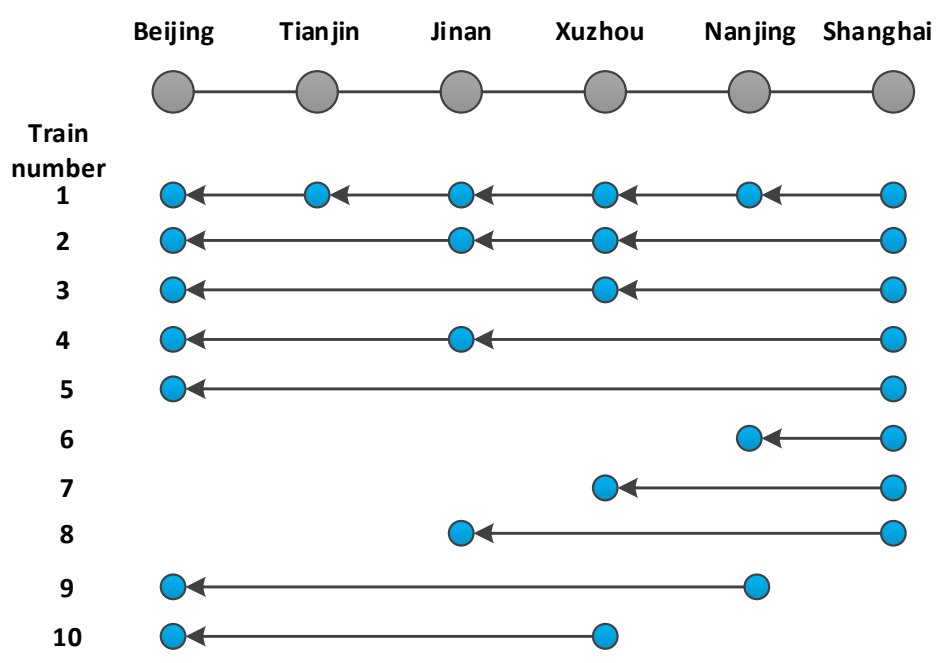

Figure 6. The backup train plans for high-speed rail express in the up direction.

(2) The train candidate set scheme in the down direction

A total of 11 trains were generated from the train candidate set scheme in the down direction, as shown in Table 4 and Figure 7.

Table 4. The backup train plans for high-speed rail express in the down direction.

\begin{tabular}{cccc}
\hline Train Number & Origin & Destination & Stop \\
\hline 1 & Beijing & Shanghai & Tianjin, Jinan, Xuzhou, Nanjing \\
2 & Beijing & Tianjin & - \\
3 & Beijing & Jinan & - \\
\hline 4 & Beijing & Xuzhou & - \\
5 & Beijing & Nanjing & - \\
6 & Beijing & Shanghai & Xuzhou \\
7 & Beijing & Shanghai & Nanjing \\
8 & Beijing & Shanghai & Jinan \\
9 & Beijing & Shanghai & Jinan, Xuzhou \\
10 & Beijing & Shanghai & Xuzhou, Nanjing \\
11 & Beijing & Shanghai &
\end{tabular}

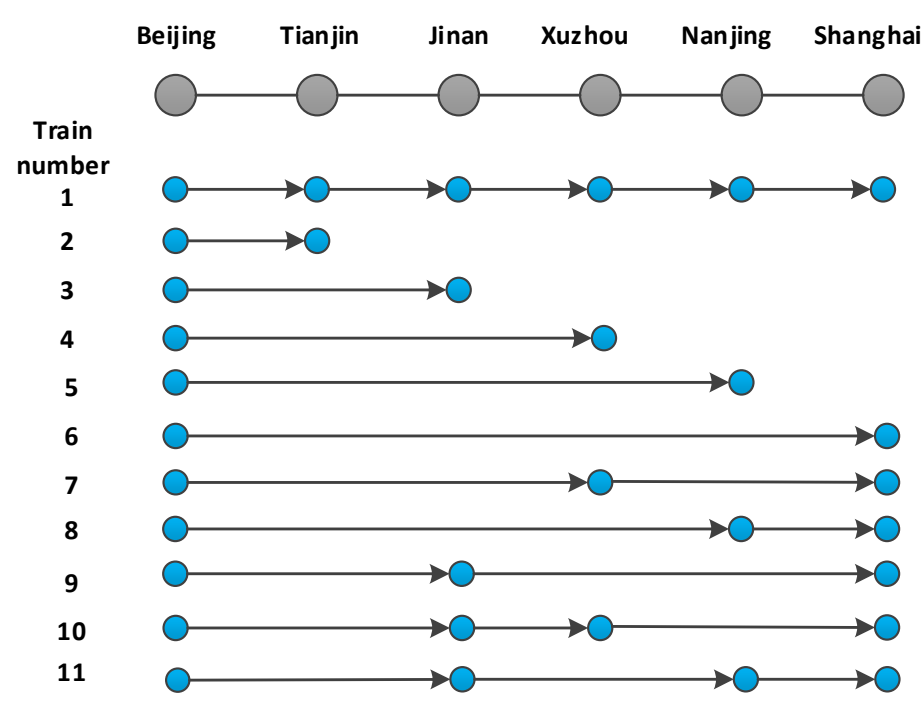

Figure 7. The backup plan for high-speed rail express trains in the down direction. 
From the analysis of the backup plan for high-speed rail express trains in the up and down direction, it can be seen that the train candidate set obtained by the column generation algorithm was in line with the OD transportation demand of the express goods between cities, and had a good emphasis on the important source occurrence and the attraction of the city in the train opening and stopping. It could also provide a good basis for the next stage of the cargo distribution.

\subsection{The High-Speed Rail Express Train Operation Plan}

The cargo distribution model was used based on the first stage train candidate set model. As mentioned above, at this stage, to obtain the optimal train operation plan at this stage, we considered the revenue of the railway express train, which aimed to minimize the number of trains, the stops, and the tonnage of the empty transport.

(1) The train operation plan for up direction

To meet the freight demand in the up direction, the train operation plan is shown in Table 5.

Table 5. The final train plan for the up direction of high-speed rail express.

\begin{tabular}{cccc}
\hline Train Number & O-D & Stop & Frequency (Train/Day) \\
\hline 1 & Shanghai-Beijing & Nanjing, Xuzhou, Jinan, Tianjin & 2 \\
2 & Shanghai-Beijing & Xuzhou, Jinan & 1 \\
3 & Shanghai-Beijing & Xuzhou & 1 \\
5 & Shanghai-Beijing & - & 2 \\
6 & Shanghai-Nanjing & - & 2 \\
7 & Shanghai-Xuzhou & - & 2 \\
\hline
\end{tabular}

The specific flow distribution scheme is shown in Figure 8.

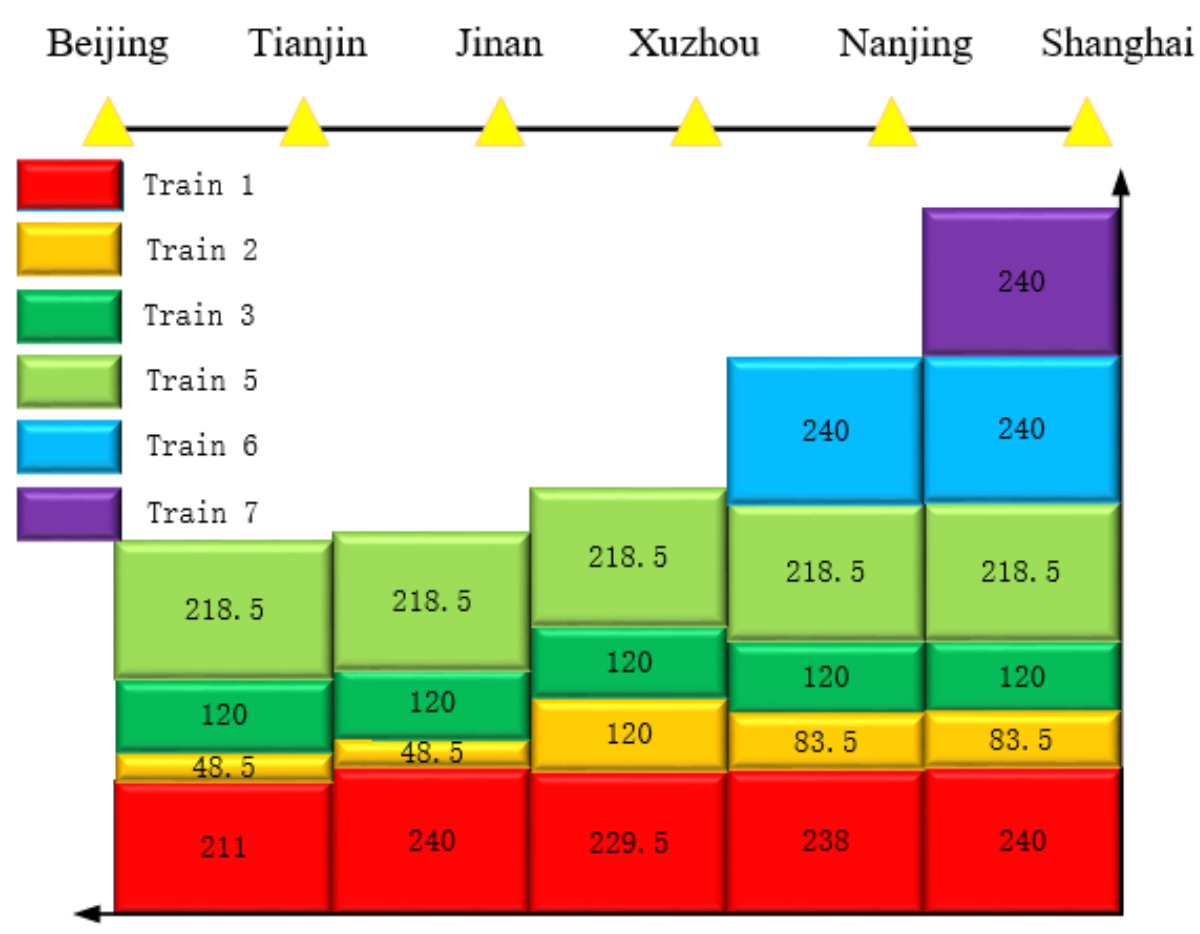

Figure 8. The section volume and its sharing of trains in the up direction.

Specific flow distribution results are shown in Table 6. 
Table 6. The result of OD volume distribution in the up direction.

\begin{tabular}{ccccc}
\hline O & D & Demands (Ton) & Number of Carrier Trains & Carrying Capacity (Ton) \\
\hline \multirow{2}{*}{ Shanghai } & Nanjing & 311 & 1 & 71 \\
& & & 6 & 240 \\
\hline \multirow{2}{*}{ Shanghai } & Xuzhou & 297 & 1 & 36 \\
& & & 7 & 21 \\
\hline Shanghai & Jinan & 153 & 1 & 70 \\
\hline \multirow{2}{*}{ Shanghai } & Tianjin & 64 & 2 & 83 \\
\hline Nanjing & Beijing & 317 & 1 & 64 \\
\hline Nanjing & Xuzhou & 22 & 3 & 98 \\
\hline Nanjing & Tinan & 15 & 5 & 219 \\
\hline Nanjing & Beijing & 5 & 1 & 15 \\
\hline Xuzhou & Jinan & 35 & 1 & 5 \\
\hline Xuzhou & Tianjin & 14 & 1 & 27 \\
\hline Xuzhou & Beijing & 58 & 1 & 35 \\
\hline Jinan & Tianjin & 19 & 1 & 14 \\
\hline Jinan & Beijing & 122 & 27 & 37 \\
\hline Tianjin & Beijing & 75 & 11 & 21 \\
\hline
\end{tabular}

In Table 6, the cargo distribution results in the up direction are very flexible. There is a huge freight demand in Shanghai, Beijing, Xuzhou, and Jinan, so 2-3 trains are required. The China Railway can provide more convenient and more sample transportation for customers according to the opening time of different trains, and further improve the service quality. Overall, there is a situation of surplus transportation capacity in Xuzhou to Jinan, Jinan to Tianjin, and Tianjin to Beijing, which is not a bad situation, as with the adjustment of China's development structure, a new region will be set up around Beijing as the vice capital of China, which will inevitably produce a new high-speed rail demand. This surplus transportation capacity could support the potential demand well. As the economic center of China, Shanghai has a close connection with the surrounding cities. The design of the high-speed rail express train operation plan can effectively meet the demand for freight transportation.

(2) The train operation plan for down direction

To meet the freight demand in the down direction, the train operation plan is shown in Table 7.

Table 7. The final train plan for the down direction of the high-speed rail express.

\begin{tabular}{cccc}
\hline Train Number & O-D & Stop & Frequency (Train/Day) \\
\hline 1 & Beijing-Shanghai & Tianjin, Jinan, Xuzhou, Nanjing & 2 \\
3 & Beijing-Jinan & - & 1 \\
6 & Beijing-Shanghai & - & 1 \\
10 & Beijing-Shanghai & Jinan, Xuzhou & 1 \\
\hline
\end{tabular}

The specific flow distribution scheme is shown in Figure 9. 


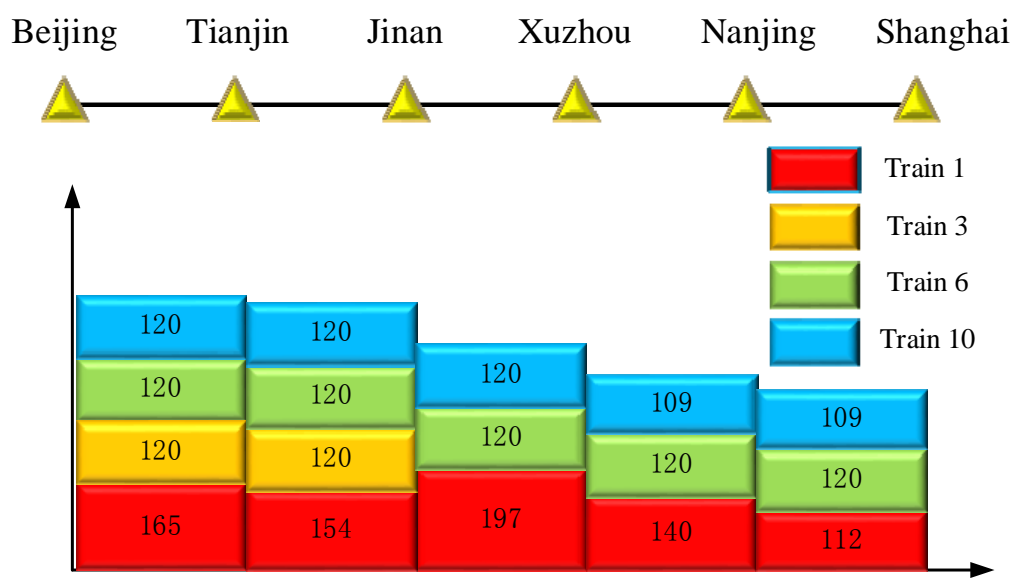

Figure 9. The section volume and its sharing of trains in the down direction.

Specific flow distribution results are shown in Table 8.

Table 8. The result of OD volume distribution in the down direction.

\begin{tabular}{|c|c|c|c|c|}
\hline $\mathbf{O}$ & $\mathbf{D}$ & Demand & Number of Carrier Trains & Carrying Capacity (Ton) \\
\hline Beijing & Tianjin & 74 & 1 & 74 \\
\hline \multirow{2}{*}{ Beijing } & \multirow{2}{*}{ Jinan } & \multirow{2}{*}{153} & 1 & 33 \\
\hline & & & 3 & 120 \\
\hline \multirow{2}{*}{ Beijing } & \multirow{2}{*}{ Xuzhou } & \multirow{2}{*}{84} & 1 & 4 \\
\hline & & & 10 & 80 \\
\hline Beijing & Nanjing & 54 & 1 & 54 \\
\hline \multirow{2}{*}{ Beijing } & \multirow{2}{*}{ Shanghai } & \multirow{2}{*}{160} & 6 & 120 \\
\hline & & & 10 & 40 \\
\hline Tianjin & Jinan & 21 & 1 & 21 \\
\hline Tianjin & Xuzhou & 16 & 1 & 16 \\
\hline Tianjin & Nanjing & 8 & 1 & 8 \\
\hline Tianjin & Shanghai & 18 & 1 & 18 \\
\hline Jinan & Xuzhou & 37 & 1 & 37 \\
\hline Jinan & Nanjing & 21 & 1 & 21 \\
\hline Jinan & Shanghai & 39 & 1 & 39 \\
\hline Xuzhou & Nanjing & 30 & 1 & 30 \\
\hline Xuzhou & Shanghai & 68 & 10 & 68 \\
\hline Nanjing & Shanghai & 55 & 1 & 55 \\
\hline
\end{tabular}

In Table 8, the operating frequency of the downlink trains and the types of train operating were obviously smaller than the up direction trains, which is mainly because Beijing is an important consumption city as the capital of China.

Further analysis of the flow distribution scheme shows that most of the OD needs are met by the same train, which facilitates the centralization of the station loading and unloading organization, thereby greatly improving the efficiency of the operation of the goods and reducing the interference to the passenger transportation.

(3) Analysis of train loading

From the above analysis, we can see that some trains have some surplus capacity in some sections. To further analyze the train loading efficiency in the train operation plan, we calculated the total loading rate of the cross section of the upstream and downstream sections, as shown in Figures 10 and 11. 


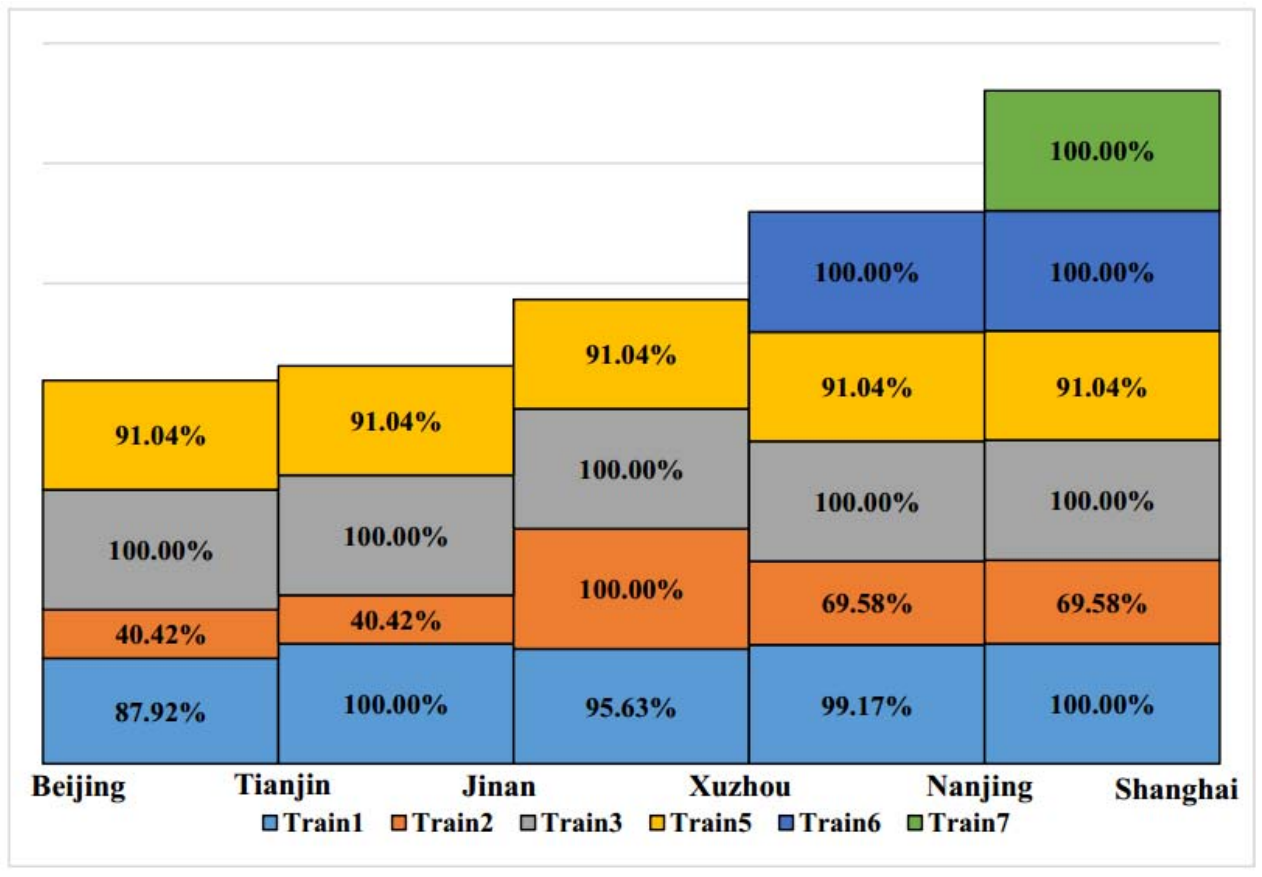

Figure 10. The loading rate of the train operation plan in the up direction.

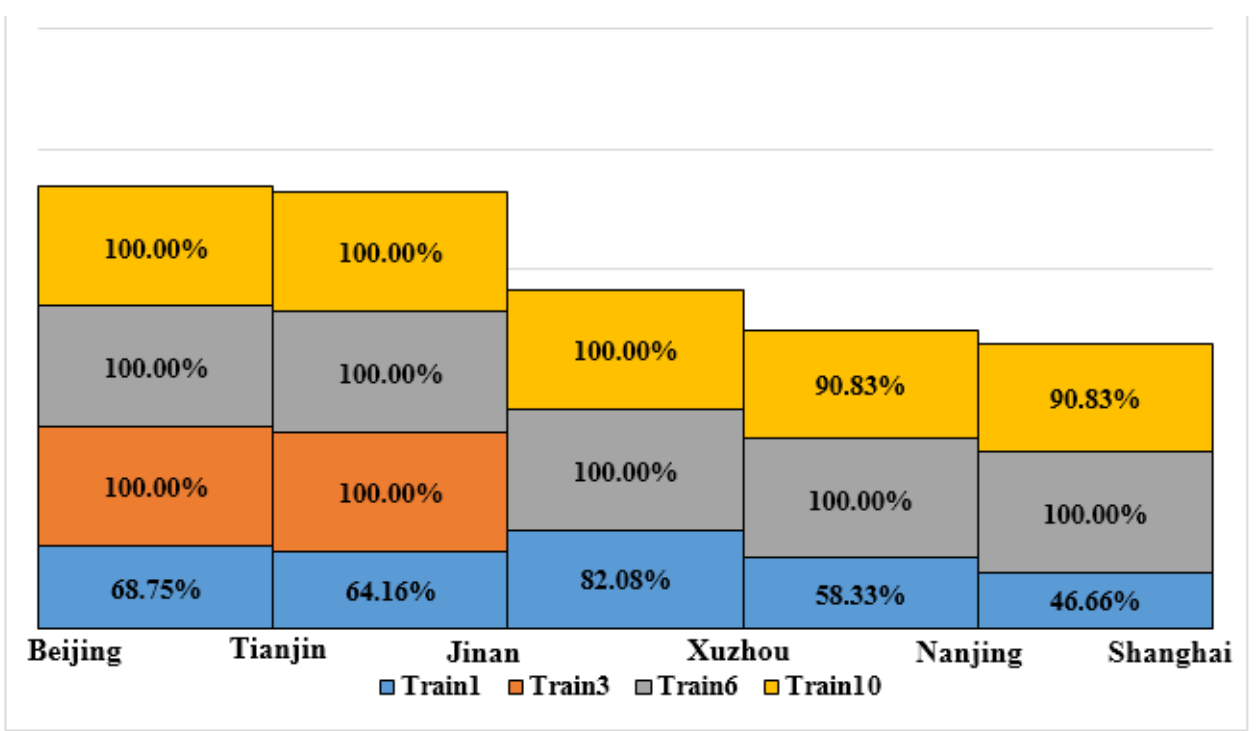

Figure 11. The loading rate of the train operation plan in the down direction.

In Figures 10 and 11, the train has a higher loading rate, regardless of the up or the down direction. Considering that the influence of the same tonnage on the economy is related to the length of the section, the overall train loading rate was calculated with the length of the transport section as the weight. The downward direction was $76.8 \%$, and the upward direction was $88.2 \%$, which further present the rationality of the model and the effectiveness of the algorithm.

At the same time, we can intuitively see the section with surplus capacity from the picture, which provides a necessary reference for the precise marketing of China Railway. There is a certain amount of surplus in the loading capacity of Train 2 in the up direction and Train 1 in the down direction. This kind of train stops more and is more flexible, which is especially suitable for communication between the large sites along the Beijing-Shanghai high-speed railway. Increasing publicity in these areas can further enhance the market share of high-speed rail express. 


\section{Conclusions}

As an economic, environmentally friendly, and efficient transport mode, high-speed railway express train has been widely recognized by the market. The design operation plan of high-speed railway express train in this paper considered the economy and practicability. From the economic point of view, the design model of the operating plan in the first stage, that is, the train candidate set generation stage, aimed at the minimum total cost and at the second stage considered the maximum total income of the train operating, which is always based on the economic benefit of the railway and helps the railway design the best overall economic scheme. The high-speed rail express train has the advantages of high efficiency and low pollution; further increasing the market occupancy rate of high-speed rail will help reduce social logistic costs and reduce pollution emissions. From a practical point of view, the operating plan designed in this paper meets all of the OD transportation needs, and the average loading rate of the scheme was above $80 \%$, which has a strong maneuverability.

Due to the incomplete transportation demand data, this study only used the Beijing-Shanghai line as an example. After obtaining more OD demand data in the future, we can consider the design of a high-speed railway train operating plan based on high-speed railway network conditions and further study the connection problem of goods based on the matching ability of the point and arc.

Author Contributions: Writing: X.Y. and M.L.; Providing case and idea: Y.G., S.-B.T., M.H., X.Y., and S.L.; and Revising: K.W., C.-H.S., and S.-B.T.

Funding: This research was supported by National Key R\&D Program of China (2017YFB1201400), National Key R\&D Program of China (2016YFE0201700) and Zhongshan City Science and Technology Bureau Project (No. 2017B1015).

Conflicts of Interest: The authors declare no conflict of interest.

\section{Abbreviations}

(1) Sets

$T \quad$ Set of the high-speed rail express trains, $i \in T$.

$\phi \quad$ Set of the stations.

$\varepsilon \quad$ Set of the sections, $(j, k) \in \varepsilon$

$\Omega \quad$ Set of the OD, $\omega \in \Omega$

$\Omega_{j k} \quad$ Set of the sections that the train needs to pass through.

(2) Parameters

Q $P_{\omega} \quad$ Total flow of goods between $\omega$.

$p_{\omega} \quad$ Transportation cost of unit weight goods between $\omega$.

$C_{r s} \quad$ Section capacity ability.

$c_{i}^{T} \quad$ The fixed cost of train $i$ operation.

$c_{i}^{V} \quad$ The unit distance variable cost of train $i$ operation.

$c_{i}^{S} \quad$ One stop cost of train $i$ operation.

$c^{L} \quad$ Loading and unloading cost of unit weight goods.

$d_{j k}^{i} \quad$ Running distance of train $i$.

$e_{i} \quad$ Stop number of train $i$.

$V_{i} \quad$ The load of the train $i$.

$M \quad$ Infinite positive number

(3) Decision variables

$\begin{array}{ll}x_{i}^{s} & \text { Equals } 1 \text { if the train } i \text { stops at station } s, 0 \text { otherwise. } \\ y_{i}^{\omega} & \text { Equals } 1 \text { if the train } i \text { serves } \omega, 0 \text { otherwise. } \\ z_{j k}^{i} & \text { Equals } 1 \text { if the train } i \text { passes though the section }(i, j), 0 \text { otherwise. } \\ k_{s}^{O_{\omega} / D_{\omega}} & \text { Equals } 1 \text { if the station } s \text { is the origin or destination of } \omega, 0 \text { otherwise. } \\ f_{i} & \text { The operating frequency of train } i . \\ q_{\omega}^{i} & \text { The volume of freight transported by the train } i \text { between } \omega .\end{array}$




\section{References}

1. Chen, F.; Shen, X.; Wang, Z.; Yang, Y. An Evaluation of the Low-Carbon Effects of Urban Rail Based on Mode Shifts. Sustainability 2017, 9, 401. [CrossRef]

2. Armah, F.A.; Yawson, D.O.; Pappoe, A.A.N.M. A Systems Dynamics Approach to Explore Traffic Congestion and Air Pollution Link in the City of Accra, Ghana. Sustainability 2010, 2, 252-265. [CrossRef]

3. Jeong, S.J.; Lee, C.G.; Bookbinder, J.H. The European freight railway system as a hub-and-spoke network. Transp. Res. Part A Policy Pract. 2007, 41, 523-536. [CrossRef]

4. Troche, G. Activity-Based Rail Freight Costing A Model for Calculating Transport Costs in Different Production Systems. Ph.D. Thesis, KTH Royal Institute of Technology, Stockholm, Sweden, 2009.

5. Pazour, J.A.; Meller, R.D.; Pohl, L.M. A model to design a national high-speed rail network for freight distribution. Transp. Res. Part A 2010, 44, 119-135. [CrossRef]

6. Fukasawa, R.; Aragão, M.V.P.D.; Porto, O.; Uchoa, E. Solving the Freight Car Flow Problem to Optimality. Electron. Notes Theor. Comput. Sci. 2002, 66, 42-52. [CrossRef]

7. Racunica, I.; Wynter, L. Optimal location of intermodal freight hubs. Transp. Res. Part B 2008, 39, $453-477$. [CrossRef]

8. Cao, X.; Lin, B.; Yan, H. Optimization of direct freight train service in the loading place. J. China Railw. Soc. 2006, 28, 6-11.

9. Liang, D.; Lin, B. Research on the Model of Optimizing Strategically Dynamic Railcar Operation. Syst. Eng. Theory Pract. 2007, 27, 77-84.

10. Li, Y.; Wu, S.; Peng, Q. Network model and algorithm for freight train marshalling plan. J. Southwest Jiaotong Univ. 2002, 37, 68-71.

11. Li, X.; Lu, H. Optimization of train formation diagram of express freight. China Railw. Sci. 2004, 25, 117-120.

12. Godwin, T.; Gopalan, R.; Narendran, T.T. A heuristic for routing and scheduling freight trains in a passenger rail network. Int. J. Logist. Syst. Manag. 2007, 3, 101-133. [CrossRef]

13. Bożejko, W.; Grymin, R.; Pempera, J. Scheduling and Routing Algorithms for Rail Freight Transportation. Procedia Eng. 2017, 178, 206-212. [CrossRef]

14. Kaspi, M.; Raviv, T. Service-Oriented Line Planning and Timetabling for Passenger Trains. Transp. Sci. 2013, 47, 295-311. [CrossRef]

15. Tsai, S. Using the DEMATEL Model to Explore the Job Satisfaction of Research and Development Professionals in China's Photovoltaic Cell Industry. Renew. Sustain. Energy Rev. 2018, 81, 62-68. [CrossRef]

16. Lee, Y.; Hsiao, Y.; Peng, C.; Tsai, S.; Wu, C.; Chen, Q. Using Mahalanobis-Taguchi System, Logistic Regression and Neural Network Method to Evaluate Purchasing Audit Quality. Proc. Inst. Mech. Eng. Part B J. Eng. Manuf. 2015, 229, 3-12. [CrossRef]

17. Lee, Y.; Chen, C.; Tsai, S.; Wang, C. Discussing green environmental performance and competitive strategies. Pensee 2014, 76, 190-198.

18. Liu, B.; Li, T.; Tsai, S. Low carbon strategy analysis of competing supply chains with different power structures. Sustainability 2017, 9, 835. [CrossRef]

19. Qu, Q.; Tsai, S.; Tang, M.; Xu, C.; Dong, W. Marine ecological environment management based on ecological compensation mechanisms. Sustainability 2016, 8, 1267. [CrossRef]

20. Lee, Y.; Wang, Y.; Chien, C.; Wu, C.; Lu, S.; Tsai, S.; Dong, W. Applying revised gap analysis model in measuring hotel service quality. SpringerPlus 2016, 5, 1191. [CrossRef] [PubMed]

21. Wang, J.; Yang, J.; Chen, Q.; Tsai, S. Collaborative Production Structure of Knowledge Sharing Behavior in Internet Communities. Mob. Inf. Syst. 2016, 2016, 8269474. [CrossRef]

22. Tsai, S.; Lee, Y.; Guo, J. Using modified grey forecasting models to forecast the growth trends of green materials. Proc. Inst. Mech. Eng. Part B J. Eng. Manuf. 2014, 228, 931-940. [CrossRef]

23. Tsai, S.; Zhou, J.; Gao, Y.; Wang, J.; Li, G.; Zheng, Y.; Ren, P.; Xu, W. Combining FMEA with DEMATEL Models to Solve Production Process Problems. PLoS ONE 2017. [CrossRef] [PubMed]

24. Ge, B.; Jiang, D.; Gao, Y.; Tsai, S. The influence of legitimacy on a proactive green orientation and green performance: A study based on transitional economy scenarios in china. Sustainability 2016, 8, 1344. [CrossRef]

25. Lee, S.; Su, J.; Tsai, S.; Lu, T.; Dong, W. A comprehensive survey of government auditors' self-efficacy and professional Development for improving audit quality. SpringerPlus 2016, 5, 1263. [CrossRef] [PubMed] 
26. Chen, H.; Wu, C.; Tsai, S.; Yu, J.; Wang, J.; Zheng, Y. Exploring key factors in online shopping with a hybrid model. SpringerPlus 2016, 5, 2046. [CrossRef] [PubMed]

27. Lee, Y.; Wang, Y.; Lu, S.; Hsieh, Y.; Chien, C.; Tsai, S.; Dong, W. An empirical research on customer satisfaction study: A consideration of different levels of performance. SpringerPlus 2016, 5, 1577. [CrossRef] [PubMed]

28. Wang, J.; Yang, J.; Chen, Q.; Tsai, S. Creating the sustainable conditions for knowledge information sharing in virtual community. SpringerPlus 2016, 5, 1019. [CrossRef] [PubMed]

(C) 2018 by the authors. Licensee MDPI, Basel, Switzerland. This article is an open access article distributed under the terms and conditions of the Creative Commons Attribution (CC BY) license (http:/ / creativecommons.org/licenses/by/4.0/). 